\title{
Science Communication and Role of Scientists for Sustainable Development in India in the Last Decade: A Critical Study
}

\author{
Ratul Datta ${ }^{1}$, Prof. (Dr.) Tapati Basu ${ }^{2}$ \\ Ph.D. Research Scholar, Department of Journalism and Mass Communication, University of Calcutta, India ${ }^{1}$ \\ Professor, Department of Journalism and Mass Communication, University of Calcutta, India ${ }^{2}$
}

\begin{abstract}
There is no denying the fact that, there is an increasing call for scientists and engineers to engage with the public more and more through mass media for sustainable development. The scenario of India is somehow different form the global scenario. Whether science journalism is one of the numerous casualties in the media meltdown in India is the most pertinent question of the last decade of $21^{\text {st }}$ century. The overall goal of the study was to provide evidence for funding organisations, universities and other research institutions on which they can base a workable system to reward scientists for their efforts to engage with the public. The study involved a survey of research scientists in highereducation institutes and interviews with a cross section of respondents and other relevant parties and hence 83 scientific-research institutes had been chosen throughout India. This study also includes to find the active participation of the scientists through scientific articles, regular columns, post-editorials, letters to the editor etc and hence 8 major circulated newspapers from 8 metro cities were chosen. There is a great need of policy which enable a higher proportion of younger scientists to get involved in public engagement and the need to reward public engagement activity in the career progression of scientists.
\end{abstract}

Keywords: Mass media, Sustainable development, Science communication, Media meltdown, Post editorials.

\section{CONTEXT AND INTRODUCTION}

Science should inspire the nation. It is important to expand the offering for those that are already interested in science and reach out to new audiences. By working together and partnering with other organisations, such as the BBC, the scientific community can expand and amplify its reach. History shows that in the olden periods, India made great strides in mathematics, agriculture, medicine and health science, astronomy, geography and diffused the generated knowledge worldwide. However, due to the complex Indian traditional multi-lingual and multi-complex culture, which emphasised social order, individual self-cultivation, ethical code or public morality and relatively ignored the exploring technological use of laws of nature, India lagged behind. Illiteracy rate has increased since past few decades and science communication graph has declined. Hence, in this research work, it is not the intention only to find the present scenario of science communication in print media of major cities of India. But this study will help the media professionals and academicians of different regional languages of this multilingual country and the kind of problems that they are facing in their profession regarding to communicate science and various local scientific issues for sustainable development.

As far as coverage of science and technology in mass media is concerned, in developing countries, like India, it will increase in near future significantly, as very fast and rapid developments are taking place. Various forms for presentation are being used to make science communication more interesting and enjoyable, such as science news, report, article, feature, story, play, poem, interview, discussion, lecture, documentary, docu-drama, scientoon (science + cartoon), satire, etc. Our science communication efforts are aimed at various target groups, such as, common man, children, students, farmers, women, workers or specialists, etc. It is obvious that, generally, when we talk about science communication, it obviously incorporates science popularization, scientific temper, technological temper and technology communication. Here, obviously comes the pragmatic role of scientists.

\section{DEFINITION OF SUSTAINABLE DEVELOPMENT}

Sustainable means capable of being sustained. Sustainable development is defined as a process of meeting human development goals while sustaining the ability of natural systems to continue to provide the natural resources and ecosystem services upon which the economy and society depends. While the modern concept of sustainable development is derived most strongly from the 1987 Brundtland Report, it is rooted in earlier ideas about sustainable forest management and twentieth century environmental concerns. As the concept developed, it has shifted to focus more on economic development, social development and environmental protection for future generations. 
Sustainable development is the organizing principle for sustaining finite resources necessary to provide for the needs of future generations of life on the planet. It is a process that envisions a desirable future state for human societies in which living conditions and resource-use continue to meet human needs without undermining the "integrity, stability and beauty" of natural biotic systems. It was suggested that "the term 'sustainability' should be viewed as humanity's target goal of human-ecosystem equilibrium (homeostasis), while 'sustainable development' refers to the holistic approach and temporal processes that lead us to the end point of sustainability."

\section{BACKGROUND OF THE STUDY}

In many newspaper of India, circulations have dropped, advertising has dried up and newspapers have been forced to lay off reporters and scale back coverage. A similar slump has hit the broadcast market, with no end in sight. An average citizen is unlikely to search the web for the Higgs boson or the proteasome if he or she doesn't hear about it first on, say, a cable news channel. And as mass media sheds its scientific expertise, science's mass-market presence will become harder to maintain. Scientists need to engage more fully with the public.

The scientists and science communicators both recognises this, and is keen to ensure that such engagement is helpful and effective. The role of science in public policy is becoming ever more pervasive. Many scientists are willing to engage in dialogue and debate, but they need encouragement and guidance, and they need to feel that their efforts are valued.

According to Nora C. Quebral (University of London, December 2011), it is the art and science of human communication, applied to the speedy transformation of a country and the mass of its people from poverty to a dynamic state of economic growth that makes possible greater social equality and the larger fulfilment of human potential. The process of overall development thorough science-based news for information dissemination in the Southeast Asian countries in the last decade could be very pragmatic, realistic, vital and hence crucial in this regard. Whether science journalism is one of the numerous casualties in the media meltdown in those countries is the most pertinent question of the last decade of $21^{\text {st }}$ century. A free press is closely linked to access to information and the protection of human rights, but the trend in this regard is discouraging.

\section{SUSTAINABLE DEVELOPMENT GOALS}

Goal-1: End poverty in all its forms everywhere

Goal 2: End hunger, achieve food security and improved nutrition and promote sustainable agriculture

Goal 3: Ensure healthy lives and promote well-being for all at all ages

Goal 4: Ensure inclusive and equitable quality education and promote lifelong learning opportunities for all
Goal 5: Achieve gender equality and empower all women and girls

Goal 6: Ensure availability and sustainable management of water and sanitation for all

Goal 7: Ensure access to affordable, reliable, sustainable and modern energy for all

Goal 8: Promote sustained, inclusive and sustainable economic growth, full and productive employment and decent work for all

Goal 9: Build resilient infrastructure, promote inclusive and sustainable industrialization and foster innovation

Goal 10: Reduce inequality within and among countries

Goal 11: Make cities and human settlements inclusive, safe, resilient and sustainable

Goal 12: Ensure sustainable consumption and production patterns

Goal 13: Take urgent action to combat climate change and its impacts

Goal 14: Conserve and sustainably use the oceans, seas and marine resources for sustainable development

Goal 15: Protect, restore and promote sustainable use of terrestrial ecosystems, sustainably manage forests, combat desertification, and halt and reverse land degradation and halt biodiversity loss

Goal 16: Promote peaceful and inclusive societies for sustainable development, provide access to justice for all and build effective, accountable and inclusive institutions at all levels

Goal 17: Strengthen the means of implementation and revitalize the global partnership for sustainable development

\section{OBJECTIVE OF THE STUDY}

The overall goal of the study was to provide evidence for funding organisations, universities and other research institutions on which they can base a workable system to reward scientists for their efforts to engage with the public. The study involved a survey of research scientists in higher-education institutes and interviews with a cross section of respondents and other relevant parties. This study also includes to find the active participation of the scientists through scientific articles, regular columns, posteditorials, letters to the editor etc.

\section{A SIX OBJECTIVES}

to establish the relative importance of science communication to Indian researchers;

- to examine the amount and type of science communication activities undertaken by Indian researchers;

- to explore factors that may facilitate or inhibit science communication;

to explore the extent to which researchers may wish to undertake further science communication;

to explore the views of funders, senior academics, social scientists and other relevant groups on factors affecting research scientists engaging in science communication activities; and 
Vol. 4, Issue 2, February 2017

- to provide evidence about how universities, other research institutions and funders can promote effective science communication.

\section{RESEARCH METHODOLOGY}

This is a social and scientific research based on different information that has been obtained from various sources. To discover the new facts and analyzing the old facts is the main motto of this research work. Here, it has been tried to find the inter-relationship between development of the society and the role of print media, basically newspaper, with role of scientific knowledge within a theoretical frame of reference. It is also the ex post-facto research as there is no control over the variables. It is also a special type of historical research work, as many historical resources as primary and secondary data has been used in this research. It is also the exploratory research work as various persons of different occupation and from different cities across India has been interviewed to gain a better understanding of the linkage in different area.

\section{RESEARCH DESIGN AND SAMPLE SURVEY}

Major scientific institutes of India having research funds from various sources are on the major thrust areas viz. Agricultural science, Biological science, Chemical and Bio-tech science, Physical and Mathematical science, Earth Science, Engineering science, Material and Metallurgical science and multi disciplinary science. There are 29 states and 7 union territories and from there 83 research institutes were considered for sample survey.

\section{A SCIENTIFIC AND RESEARCH INSTITUTES}

There are various no of different scientific and research institutes throughout India and the cultivation of their active participation are needed. Hence various agricultural, earth science related, physical and mathematical science based institutes were considered as sample.

For 17 agricultural science institutes-Indian Agricultural Research Institute (IARI) for New Delhi, Indian Institute of Horticultural Research for Karnataka, Agharkar Research Institute for Maharashtra, National Research Centre on Meat for Andhra Pradesh and Telengana, National Dairy Research Institute for Haryana, Forest Research Institute for Uttarakhand, Institute of Forest Genetics and Tree Breeding for Tamil Nadu, Tropical Forest Research Institute for Madhya Pradesh, Indian Veterinary Research Institute for Uttar Pradesh, Central Institute of Post-Harvest Engineering \& Technology for Punjab, Central Marine Fisheries Research Institute for Kerala, Central Institute of Freshwater Aquaculture for Odisha, Central Potato Research Institute for Himachal Pradesh, Central Sheep and Wool Research Institute for Rajasthan, Central Inland Fisheries Research Institute for West Bengal, National Research Centre for Groundnut for Gujarat, Indian Council of Agricultural Research for Meghalaya were considered. But no major scientific institutes on agriculture has been found from Jammu and Kashmir, Andaman \& Nicobar Island, Chattishgarh, Goa, Jharkhand and all North-east Indian states.

For 15 Biological and Medical science institutes-Indian Institute of Integrative Medicine from J\&K, International Centre for Genetic Engineering and Biotechnology from New Delhi, Adyar Cancer Institute from Tamil Nadu, National Institute of Virology from Maharashtra, Center for DNA Fingerprinting and Diagnostics from Andhra Pradesh and Telengana, Institute of Life Sciences from Orissa, National Brain Research Centre from Punjab, Central Food Technological Research Institute from Karnataka, Sree Chitra Tirunal Institute for Medical Sciences \& Tech from Kerala, Central Institute of Medicinal and Aromatic Plants from Uttar Pradesh, Guru Ghasidas University from Chhattisgarh, Bose Institute from West Bengal, Regional Medical Research Centre from Andaman \& Nicobar Island, Centre for Chronic Disease Control from Haryana, School of Pharmacy \& Research from Madhya Pradesh.

For 7 Chemical and Bio-tech science institutes-Indian Institute of Chemical Technology for Telengana and Andhra Pradesh, Central Electrochemical Research Institute for Tamil Nadu, Indian Institute of Petroleum for Uttarakhand, Central Salt \& Marine Chemicals Research Institute for Gujarat, National Chemical Laboratory for Maharashtra, National Institute of Pharmaceutical Education and Research for Punjab and Laboratory of Advanced Research in Polymeric Materials for Orissa were considered.

For 8 Physical and Mathematical science institutesDepartment of Physics, Karunya University for Tamilnadu, Inter-University Accelerator Centre for New Delhi, S. N. Bose National Centre for Basic Sciences for West Bengal, Raman Research Institute for Karnataka, Aryabhatta Research Institute for Observational Sciences for Uttarakhand, Department of Department of Physics St. Thomas College for Kerala and Physical Research Laboratory for Gujarat were considered.

For 9 Earth Science institutes-Centre for Marine Living Resources \& Ecology for Kerala, National Geophysical Research Institute for Andhra Pradesh and Telengana, Wadia Institute of Himalayan Geology for Uttarakhand, National Institute of Ocean Technology for Tamil Nadu, Birbal Sahni Institute of Palaeobotany for Uttar Pradesh, Centre For Advanced Study, Department of Geology, University of Delhi for New Delhi, The Post-graduate Department of studies in Earth Science, The University of Mysore for Karnataka, National Centre for Antarctic and Ocean Research for Goa, Indian school for Mines for Jharkhand were considered.

For 11 Engineering science institutes-Central Mechanical Engineering Research Institute for West Bengal, Central Scientific Instruments Organisation for Punjab, Central Manufacturing Technology Institute for 
Karnataka, Structural Engineering Research Centre for 8\% Listening, understanding public, involving in science, Tamil Nadu, Central Building Research Institute for science-based debates, science-based decisions (D)

Uttarakhand, Centre for Development of Advanced $8 \%$ Communicating with or speaking to the public, Computing for Maharashtra, Indian Institute of speaking in public, lectures, shows (E)

Information Technology for Uttar Pradesh, Central Road 10\% Explaining the process of science, what is done, why, Research Institute for New Delhi, Indian Institute of limitations (F)

Information Technology and Management for Madhya 9\% Talking to schools, inspiring young people (G)

Pradesh, National Council of Cement and Building Materials for Haryana, Central Electronics Engineering Research Institute, CSIR for Rajasthan were considered.

For 7 Material and Metallurgical science institutesInstitute of Minerals and Materials Technology for Orissa, Central Glass and Ceramic Research Institute for West Bengal, National Metallurgical Laboratory for Jharkhand, Indian Plywood Industries Research \& Training Institute for Telengana and Andhra Pradesh, Indian Institute of Technology for Maharashtra, Indian Institute of Metals of Karnataka were considered.

For 9 Multi disciplinary science institutes- National Institute of Science Technology and Development Studies in New Delhi, National Institute for Inter-disciplinary Science and Technology for Kerala, National Environmental Engineering Research Institute for Maharashtra, Pushpa Gujral Science City of Punjab, National Council of Science Museums (NCSM) of West Bengal, North East Institute of Science and Technology of Assam, Centre for Ecological Sciences, Indian Institute of Science of Karnataka, NALSAR University of Law of Telengana and Andhra Pradesh and Indian Institute of Remote Sensing of Uttarakhand were considered.

\section{B. 8 NEWSPAPERS FROM 8 METRO CITIES}

For sample survey of newspapers in the last decade, 8 metro cities along with 8 major circulated newspapers were considered. From Kolkata, The Telegraph was considered. Similarly, Mumbai Mirror for Mumbai, Hindustan Times for Delhi, The Hindu for Chennai, The Assam Tribune for Assam, The Times of India for Jaipur, The Central Chronicle for Nagpur and Deccan Herald for Hyderabad were considered. Then every $5^{\text {th }}$ day and its multiple i.e. $10^{\text {th }}, 15^{\text {th }}, 20^{\text {th }}, 25^{\text {th }}$ and $30^{\text {th }}$ day was taken as sample for each month of each newspaper and different types of columns, post editorials etc were tried to be found according to the space share. Hence, for each newspaper, a total of 720 issues for the last decade were taken.

\section{RESULTS-1 RESEARCH QUESTIONS AND RESULTS FOUND FROM THE SCIENCE- RESEARCH INSTITUTES}

RQ-1 Scientists are being asked to engage more with the non-specialist public. What does this mean to you?

$24 \%$ Informing, explaining, promoting science (A)

26\% Communication through Media (B)

$15 \%$ Implications, relevance, utility of research, value of science $(\mathrm{C})$

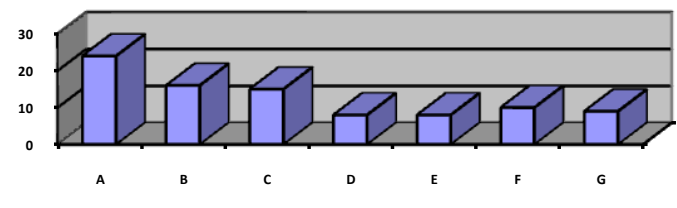

Diagram 1 for RQ-1

RQ-2 How important do you feel it is that you personally, in your current post, directly engages with each of the following groups about your research? Please rate importance on a scale of 1 to 5 , where 1 is not important and 5 is very important (Left to Right)

Q2a General journalists (i.e. in press, TV and radio) $25 \%$ $22 \% 22 \% 21 \% 10 \%$

Q2b Popular science journalists (e.g. on New Scientist) $11 \% 18 \% 25 \% 27 \% 19 \%$

Q2c Schools and school teachers 14\% 15\% 21\% 30\% 20\% Q2d Policy-makers 9\% 11\% 20\% 25\% 35\%

Q2e Industry / business community $12 \% \quad 17 \% \quad 24 \% \quad 25 \%$ $22 \%$

Q2f The non-specialist public 11\% 19\% 31\% 27\% 12\%

Q2g Non-Governmental organisations (NGOs) 15\% 19\% $31 \% 23 \% 12 \%$

RQ-3 Which of these groups do you find it easiest to talk with about your research?

$16 \%$ Policy-makers

$22 \%$ Young people in schools

$29 \%$ Industry / business community

14\% Young people outside school

$29 \%$ Popular science journalists

$21 \%$ The non-specialist public

$12 \%$ General journalists

$10 \%$ NGOs (non-Governmental organisations)

$9 \%$ Others in the media such as documentary and other programme makers

$20 \%$ Patients / patient groups

$17 \%$ Press officers in your institution

$19 \%$ None / Don't know

$23 \%$ Schools and school teachers

RQ-4 Which of these groups do you find it hardest to talk with about your research?

$19 \%$ Policy-makers

$7 \%$ Young people in schools

$12 \%$ Industry / business community

$11 \%$ Young people outside school

$6 \%$ Popular science journalists

$15 \%$ The non-specialist public 
Vol. 4, Issue 2, February 2017

$21 \%$ General journalists (i.e. in press, TV and radio)

$5 \%$ Non-Governmental organisations (NGOs)

$10 \%$ Others in the media such as writers, documentary and other programme makers

4\% Patients / patient groups

$5 \%$ Press officers in universities

$47 \%$ None / don't know

$6 \%$ School teachers

RQ-5 Thinking about public engagement with, and communication about, science, roughly how many times in the past 12 months have you done each of the following? ( From Left to Right-None/ Once/ 2-3 times / 4-5 times/ More than 5 times)

Q5a Worked with teachers / schools $70 \% \quad 15 \% \quad 10 \% \quad 2 \%$ $3 \%$

Q5b Participated in an institutional open day $44 \% 36 \%$ $14 \% 5 \% 2 \%$

Q5c Given a public lecture, including being part of a panel $60 \% 21 \% 14 \% 3 \% 2 \%$

Q5d Taken part in a public dialogue event / debate $80 \%$ $13 \% 6 \% 1 \% 1 \%$

Q5e Been interviewed on radio 88\% 7\% 4\% $1 \%$ 1\%

Q5f Been interviewed by a newspaper journalist 77\% 13\% $8 \% 2 \% 1 \%$

Q5g Written for the non-specialist public 75\% $15 \% 8 \%$ $1 \% 1 \%$

Q5h Engaged with policy-makers 67\% 16\% 11\% 2\% 4\%

Q5i Engaged with non-Governmental organisations (NGOs) $77 \%$ 9\% 8\% 2\% 4\%

Q5j Worked with science centres / museums 87\% 6\% 5\% $1 \% 1 \%$

Q5k Judged competitions 89\% 8\% 2\% 1\%*

RQ-6 How important is it to you that you find time to engage with the media?

$10 \%$ Not at all important (A)

$42 \%$ Not very important (B)

$21 \%$ Equally important (C)

$19 \%$ Fairly important (D)

$9 \%$ Very important $(\mathrm{E})$
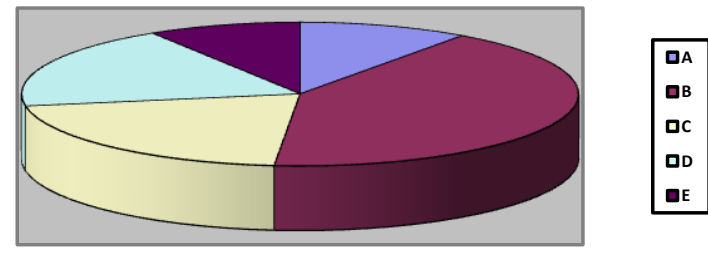

Diagram 2 for RQ-6

RQ-7 What do you think is the main drawback to scientists and engineers generally engaging with the non-specialist public?

$6 \%$ It makes them a target

$15 \%$ It can send out the wrong messages

$1 \%$ It diverts money from research projects
$29 \%$ It takes up time that is better used on research $35 \%$ It will give to feedback in their scientific carrier $11 \%$ Unable to know how to use media for better science communication

$3 \%$ It takes up time that is better used on other, nonresearch, activities.

RQ-8 Would you like to spend more time, less time or about the same amount of time as you do now engaging with the media for communicating science?

$45 \%$ I would like to spend more time

$41 \%$ I am content with the amount of time I spend on this now

$3 \%$ I would like to spend less time

$11 \%$ Don't know

RQ-9 What training, if any, have you had in communicating science to the non-specialist public through mass media?

$73 \%$ None (A)

$14 \%$ Media training on being interviewed by journalists (B)

$10 \%$ Training in writing for the non-specialist public (C)

$11 \%$ Training in speaking to the non-specialist public (D)

$3 \%$ Training in understanding the UK school education system (E)

4\% Training in speaking to school children (of any age)

(F)

$3 \%$ [Other] Informal means / experience $(\mathrm{G})$
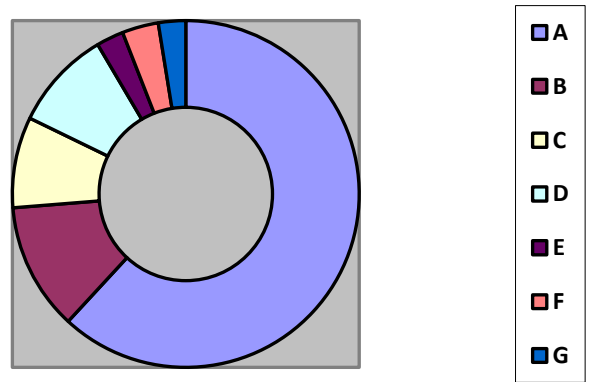

Diagram 3 for RQ-9

RQ-10 How easy or difficult do you think it is to get involved in science communication through any media for those who want to do so?

$4 \%$ Very easy

$6 \%$ Very difficult

$24 \%$ Don't know / can't say

$31 \%$ Fairly easy

$35 \%$ Fairly difficult

RQ-11 How well equipped do you personally feel you are to engage with the non-specialist public, specially journalists and general people about your research? $8 \%$ Very well equipped $24 \%$ Fairly well equipped $58 \%$ Not very well equipped $10 \%$ Not at all equipped 
Vol. 4, Issue 2, February 2017

RQ-12 What is stopping you from getting (more) $1 \%$ Clinical work only involved in activities that engage the non-specialist $2 \%$ Management/administration public in science?

4\% I am already involved enough

$2 \%$ I just don't want to

$4 \%$ I don't know how

$19 \%$ The public don't want to know / my work isn't interesting

$15 \%$ English is not my first language

$33 \%$ I do not have the training

$20 \%$ I need to spend more time on my research

$3 \%$ I need to spend more time getting funding for my research

RQ-13 Which of these best describes your current position?

$12 \%$ Professor or above

$18 \%$ Reader / senior lecturer / researcher / fellow

$26 \%$ Lecturer / researcher / fellow

20\% Assistant and Associate Professor

23\% Junior / assistant researcher / fellow/ Technician /

other support staff

$1 \%$ No reply

\section{RQ-14 Working status}

93\% Working full-time ( $>35$ hours per week)

$6 \%$ Working part-time ( $<35$ hours per week)

$1 \%$ No reply

RQ-16 From the list below, which discipline most closely describes your current area of research interest?

$16 \%$ Clinical medicine (including dentistry) (A)

$18 \%$ Non-clinical biological Science (including medical, psychology, veterinary) (B)

$21 \%$ Engineering / engineering sciences (including IT) (C)

$5 \%$ Chemical / chemical engineering (D)

$8 \%$ Physics and Mathematics (E)

$18 \%$ Environmental sciences (including earth and marine sciences) (F)

$7 \%$ Agricultural science $(\mathrm{G})$

$3 \%$ Space science $(\mathrm{H})$

$4 \%$ Earth science (I)

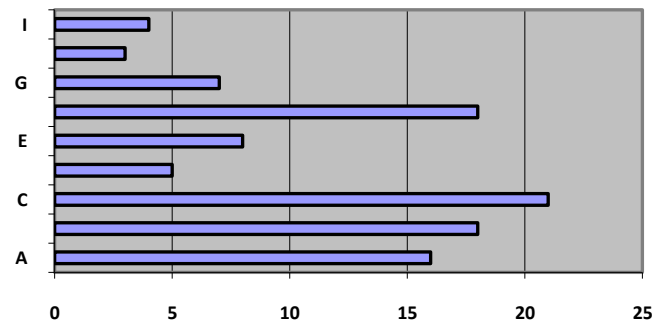

Diagram 4 for RQ-16

RQ-15 Which best describes your main role at your institution?

$50 \%$ Research (including clinical research)

46\% Research and teaching

$1 \%$ Teaching only
RQ-17 Do you think your work has implications for society and/or policy-makers and regulators?

$71 \%$ Yes

$14 \%$ No

$14 \%$ Don't know / not sure

$1 \%$ No reply

RQ-18 Regular science communication needs active participation of Scientists. Do you think so?

$73 \%$ Active participation is needed

$21 \%$ Active participation is there

$6 \%$ No need of active participation

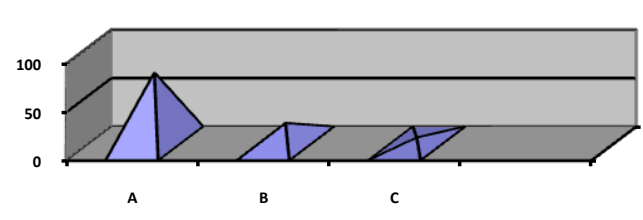

Diagram 5 for RQ-18

RQ-19 Are you:

$56 \%$ Male

$44 \%$ Female

RQ-20 What was your age last birthday?

$3 \%$ Above 60

$52 \%$ Between 50 and 60

$44 \%$ Between 40 and 50

$1 \%$ No reply

\section{RESULTS-2 ACTIVE PARTICIPATION OF SCIENTISTS IN NEWSPAPERS IN THE LAST DECADE}

It has been found from each 720 newspapers for the last decade ( 6 days $\times 12$ months $\times 10$ years) that, The Hindu has got the highest presence of scientists and researchers in all science news, followed by The Times of India. Then comes Deccan Herald, Mumbai Mirror, Hindustan Times, The Telegraph, Central Chronicle and lastly ranked the north-eastern newspaper, The Assam Tribune. All percentage were taken, considering the total science news as 100 percent. Explaining one, it can be clarified that, for The Telegraph, among 100 percent science news, only 4 percent have scientist participation and others are either from translation or from news agency or by science communicator or from any press release.

Table-1 Scientists' participation in science news

\begin{tabular}{|c|c|c|}
\hline Newspaper & Space percentage & Rank \\
\hline The Telegraph & 4 & $\mathbf{6}$ \\
\hline Mumbai Mirror & 6 & $\mathbf{4}$ \\
\hline
\end{tabular}


Vol. 4, Issue 2, February 2017

\begin{tabular}{|c|c|c|}
\hline Hindustan Times & 5 & $\mathbf{5}$ \\
\hline The Hindu & 11 & $\mathbf{1}$ \\
\hline Assam Tribune & 2 & $\mathbf{8}$ \\
\hline Times of India & 9 & $\mathbf{2}$ \\
\hline Central Chronicle & 3 & $\mathbf{7}$ \\
\hline Deccan Herald & 7 & $\mathbf{3}$ \\
\hline
\end{tabular}

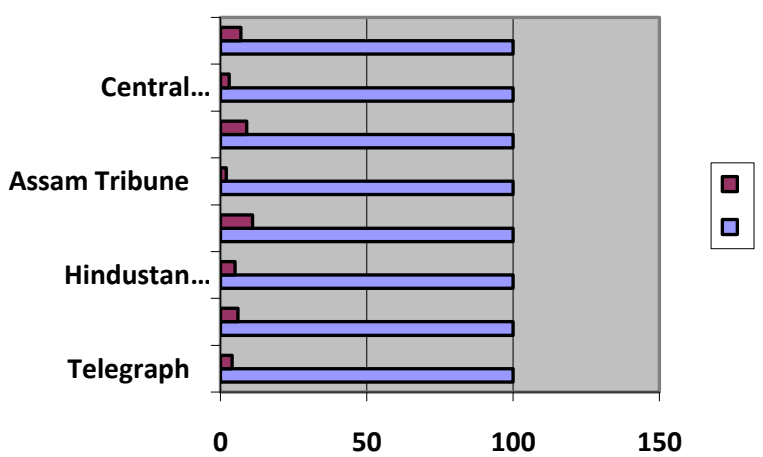

Diagram 6

\section{DISCUSSION AND LIMITATION}

This research summarises key findings from the survey and interviews, and develops conclusions and recommendations based on the views of the scientists.

These include the need for:

- greater clarity about the definition, goals, roles and objectives of public engagement among funders of research and higher education institutions before funding priorities are developed;

- an understanding, through evaluation, of what works and what does not in public engagement;

- further research and analysis on the dataset to highlight implications in relation to policy development in this area, and the placing of the raw data in the public domain to facilitate this analysis;

- a review of public engagement training at undergraduate and postgraduate level;

- the establishment of role models and advocates for public engagement;

- a more effective support system for scientists wishing to undertake public engagement, the introduction of significant departmental rewards and better recognition of the benefits of public engagement;

- policies which enable a higher proportion of younger scientists to get involved in public engagement and the need to reward public engagement activity in the career progression of scientists;

- co-ordination between funding agencies, government, higher-education institutions and learned societies on public engagement to agree approaches and achieve the desired scale of impact.

There is also some limitations, as all research institutes along with all science academicians were not been considered here, though majority were tried to be taken within this research.

\section{REFERENCES}

[1] C. Sagan, quoted in SIP Iscope (1988) 16, as communicated personally by Dr. Terry Sejnowski.

[2] K. Meenu, Coverage of S\&T in national and regional newspapers: a comparative study, Indian Journal of Science Communication (2005)

[3] Kumar, K. (1981). Mass communication in India. India: Jaico Publishing House.

[4] National Readership Study. (2005). National Readership Studies Council, Audit Bureau of Circulations, Mumbai, India. Retrieved from www.auditbureau.org

[5] Viswanathan, S. (30 September 2003). 125 years of the Hindu. Retrieved on $26 \quad$ September 2006 from www.indeconomist.com/300903_media_hindu. Html

[6] Chatterjee, P. (2008). Tatwa aru Praoygere Gana Sanjog. Guwahati, India: Bina Library.

[7] De Benedetti's, P. (n.d.). Guiding Principles for Creating Media Literacy Projects. Retrieved February 23, 2011, from www.medialiteracy.net/pdfs/guiding_princ.pdf

[8] Duncan, B., Pungente, J., \& Andersen, N. (2002). Media Education in Canada. Retrieved February 23, 2011, from http://www.aml.ca/articles/articles.php?articleID $=272$

[9] M.M. Gore and A. Mishra, Vigyan katha ka Safar, Manjuli Prakashan, New Delhi (2000).

[10] Kipping, P. (1996, Jan-Feb). Media Literacy - An Important Strategy for Building Peace. Peace Magazine, 12(1), 23

[11] Livingston, Morna \& Beach, Milo (2002), Steps to Water: The Ancient Stepwells of India, Princeton Architectural Press, ISBN 156898-324-7.

[12] Lock, Stephen etc. (2001), The Oxford Illustrated Companion to Medicine, Oxford University Press, ISBN 0-19-262950-6. Lowe, Robson (1951), The Encyclopedia of British Empire Postage Stamps, 1661-1951 (vol. 3).

[13] MSNBC (2008), "Dig uncovers ancient roots of dentistry".

[14] Nair, C.G.R. (2004), "Science and technology in free India", Government of Kerala-Kerala Call, Retrieved on 2006-07-09.

[15] O'Connor, J. J. \& Robertson, E.F. (1996), "Trigonometric functions",

[16] Partington, James Riddick \& Hall, Bert S. (1999), A History of Greek Fire and Gunpowder, Johns Hopkins University Press, ISBN 0-8018-5954-9.

[17] Rodda \& Ubertini (2004), The Basis of Civilization-Water Science?, International Association of Hydrological Science, ISBN 1-901502-57-0.

[18] Roy, Ranjan (1990), "Discovery of the Series Formula for by Leibniz, Gregory, and Nilakantha", Mathematics Magazine, Mathematical Association of America, 63 (5): 291-306.

\section{BIOGRAPHIES}

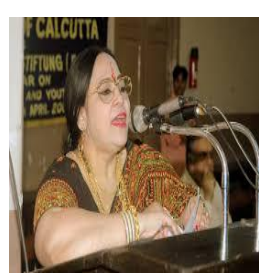

Professor (Dr.) Tapati Basu She is the Premchand Roychand Scholar (It is the only one case in Journalism and Mass Communication in its glorious 152 years history) from University of Calcutta, joined in the department of Journalism and Mass Communication of the same university as her first teaching job as a Lecturer. She was the first candidate to clear the NET GRF, SRF (National Eligibility Test) in Journalism and Mass Communication in India and started doing research in the Department of Journalism and Mass Communication in India. She has done her Post Doctorate in Universite De Paris Sorbonne, Paris in French Media. She has research work on Science Communication in French Media in Maison Des Sciences De L'Home, Paris. She is also the first Lady Professor in 
Journalism and Mass Communication in West, North, North-East and Eastern India. She was the former Dean of Arts, University of Calcutta for the $1^{\text {st }}$ time as women and was the Head of the Department for the longest time in its history. Her research works are published in different Peer Reviewed Journals. Her books are authenticated and exceptional research works. She is guiding many students for their $\mathrm{PhD}$ internationally and nationally and already many students have been awarded $\mathrm{PhD}$ under her guidance. She visited many universities internationally and obviously nationally, as visiting faculty. Presently, seniormost professor of CU.

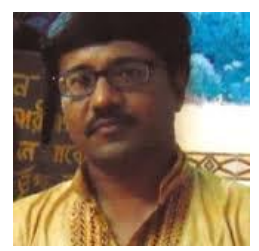

Ratul Datta With a strong background in Journalism, he completed his master degree in Journalism and Mass Communication from University of Calcutta and presently doing his Ph.D. from the same University. He is also a Gazetted officer of Department of Information and Cultural Affairs, Government of West Bengal and presently in charge of (jointly with editor) the only monthly organ of Government of West Bengal, i.e. 'Pashchimbanga'. He has a strong reporting and editing experience of print and audio-visual media for 9.5 years. He also successfully completed his course on Science Journalism under UGC and CU, from Rajabazar Science College. He stood $1^{\text {st }}$ in their project work which was published in the issue of 'Science and Culture.' His 6 research paper has already been published in Indian Science Congress Association in consecutive 6 years from 2011-2016. He is also the author of 9 books, mostly on popular science and information. He did many talks on popular science in All India Radio also. 